\title{
Mechanical Behavior and Chloride Penetration of Precracked Reinforced Concrete Beams with Externally Bonded CFRP Exposed to Marine Environment
}

\author{
Yan Xie, Kunhua Guan, Lei Zhan, and Qichen Wang \\ School of Civil and Transportation Engineering, Guangdong University of Technology, Guangzhou 510006, China \\ Correspondence should be addressed to Yan Xie; xieyan@gdut.edu.cn
}

Received 23 September 2016; Accepted 8 November 2016

Academic Editor: Baolin Wan

Copyright (C) 2016 Yan Xie et al. This is an open access article distributed under the Creative Commons Attribution License, which permits unrestricted use, distribution, and reproduction in any medium, provided the original work is properly cited.

\begin{abstract}
Cracked reinforced concrete (RC) beams can be repaired effectively by using externally bonded CFRP sheets. However, when the strengthened beams are subjected to marine environment, long-term performance will be affected by the material and the interface deterioration of concrete and CFRP. Therefore, to evaluate the service life of the strengthened beams, this study investigates the behavior of precracked RC beams strengthened with CFRP sheets exposed to marine environment. Accelerated ageing experiments were carried out by exposing specimens to cyclic wetting in sea water and drying in $40^{\circ} \mathrm{C}$ air for 3 months and 6 months, respectively. After the environment exposure, four-point bending test was conducted and then the diffusion of chlorides in the strengthened beams was analysed. The results show that the bonding behavior of the adhesive was weakened and the ductility of the strengthened beams was slightly reduced due to the marine environment. But there is no obvious strength difference between the strengthened beams suffered from marine environment for 3 months and 6 months. Besides, the precracks in the RC beams accelerated the chloride diffusion, while CFRP bonding reduced the chloride penetration. In addition, NEL method was employed to validate the effect of the cracks on chloride permeability. The results showed that the chloride diffusion coefficients increased with the depth of the cracks.
\end{abstract}

\section{Introduction}

Fatigue damage is one of the main problems that occur in highway bridges [1]. Concrete cracks induced by fatigue loadings may decrease the strength and stiffness of the reinforced concrete (RC) beams and accelerate chloride migration in concrete. To repair the cracked RC beams in the damaged bridges, external bonding of carbon fiber reinforced polymer (CFRP) sheets to the tension face was applied [2]. However, because of the adhesive bonding deterioration, the composite structures may have mechanical degradation and durability problem when they are subjected to marine environment. Thus, there is a great need to understand the durability and corrosion mechanism of the repaired RC beams under the environmental conditions.

Choo et al. [3] present a study on a RC bridge subjected to extreme vehicular loads and retrofitted with CFRP laminates. The increase in flexural capacity provides an adequate margin of safety against further overloading. The RC beams damaged by static loading repaired with externally bonded CFRP laminates were demonstrated to be effective for increasing the capacity and rigidity [4]. On the other hand, the durability of RC beams reinforced with GFRP laminates were investigated by Almusallam [5]. The test results show that none of the environmental conditions have a noticeable influence on the flexural strength of the retrofitted beams. Nevertheless, the experimental tests on the durability of the concrete strengthened with near-surface mounted CFRP laminates showed a decrease of around $12 \%$ in the maximum pull-out force due to the wetting-drying cycles [6]. Benzarti et al. [7] conducted an accelerated ageing experiment to investigate the durability of the adhesive bond between concrete and CFRP strengthening systems under $40^{\circ} \mathrm{C}$ and $95 \%$ relative humidity. The results showed that moisture diffusion from the superficial layer of concrete towards the adhesive joint is a key factor to reduce the adhesive bonding strength and degrade the behavior of 
adhesive itself. The deterioration in the adhesive bonding under temperature and water-immersion ageing conditions were detected by a nondestructive ultrasonic evaluation technique as well [8].

Besides, the effect of moisture diffusion on the adhesive bonding and chloride induced corrosion of the steel bar are also major causes of the deterioration of CFRP flexurally strengthened RC beams under marine environment [9-11]. The chloride diffusion in concrete was accelerated due to the defects of the RC beams caused by the actions of loads, environments, and climate conditions [12]. For all actions, flexural cracks in RC beams are an unavoidable phenomenon and have a significant effect on chloride diffusion [13]. Some studies [14-16] reported that crack width and depth significantly influence the chloride permeability in concrete. In addition, the cracks caused by tensile fatigue loading can accelerate the chloride penetration in concrete by 1.53.0 times [17]. When the cracks were notched artificially, however, the influence of crack width on chloride penetration is less pronounced and crack depth is the key factor of the chloride penetration [18].

From the above, the previous research has shown the influence of the marine environmental exposure on the RC beams with externally bonded CFRP. However, the effects of precracks and CFRP bonding on the chloride penetration to the concrete, as well as the durability performance of the retrofitted precracked beams, still remains unclear. In this paper, experimental study on precracked RC beams strengthened with CFRP subjected to marine environmental exposure was conducted. The deterioration of the specimens was produced by placing the beams into salt water under wetting/ drying cycles. The flexural capacity and chloride penetration were investigated after 3 and 6 months under environmental exposure. In addition, NEL method [19-21] was employed to measure the chloride permeability with the depth of the cracks in concrete.

\section{Experimental Study}

In total, 19 specimens distributed in eight series were tested, as summarized in Table 1. For each series, the specimens have equal characteristics. The series " $C$ " represents control specimens. The references "D"; "F"; and " $H$ " mean cracked status, strengthened status, and environmental exposure status, respectively. The suffixed digitals 3 and 6 indicate months of environmental exposure.

2.1. Specimens. All specimens were $\mathrm{T}$ cross section beams as shown in Figure 1, reinforced with $2 \Phi 14 \mathrm{~mm}$ steel bars in tension side and $4 \Phi 8 \mathrm{~mm}$ steel bars in compression side. They were provided with $\Phi 6 \mathrm{~mm}$ diameter steel stirrups at $100 \mathrm{~mm}$ center to center spacing and distributed over the span. The mix proportions used to cast all beams were $1: 1.81: 2.77: 4.51$ (water: cement: sand:aggregate). The average 28-day compressive strength of the concrete was $36.62 \mathrm{MPa}$. The yield and ultimate strengths of steel bars were $397 \mathrm{MPa}$ and $535 \mathrm{MPa}$, respectively. The elastic modulus is $202 \mathrm{GPa}$. The CFRP sheet (UT70-30) used was a unidirectional CFRP supplied by Toray Industries, whose nominal thickness is $0.167 \mathrm{~mm}$. The ultimate strength and the elastic modulus of the CFRP were $3878 \mathrm{MPa}$ and $244 \mathrm{GPa}$, respectively. The adhesive used was Lica-100 A/B, a two-part thixotropic epoxy resin. It had a modulus of elasticity of $3.2 \mathrm{GPa}$ and a tensile strength of $55.5 \mathrm{MPa}$.

2.2. Preparation of Strengthened Specimens. All beams were cast from the same batch in the laboratory and thereafter cured for 28 days. The RC beams in the specimen series DF, DFH-3, and DFH-6 were precracked by fatigue overloading before CFRP strengthening. The tensile concrete surface of the strengthened RC beams was ground by a concrete scabbler until exposure of aggregate was achieved, then blown with clean air to remove dust, and cleaned by acetone to ensure a good bond between the concrete surface and adhesive. After mixing, the adhesive was applied to the beam and CFRP sheet. The excess adhesive was squeezed out along the edges of the sheet, assuming complete adhesive coverage. Two layers of CFRP sheet was bonded to the tension face of the strengthened specimens. In order to avoid CFRP sheet debonding at the ends during the testing, they were attached in three U-shapes with $50 \mathrm{~mm}$ extension on each side of the beams, as shown in Figure 1.

2.3. Marine Environmental Exposure. The marine environment was produced by placing specimens into salt water under wetting/drying cycles. The wetting/drying environmental chamber with a length of $3 \mathrm{~m}$, a width of $2 \mathrm{~m}$, and a depth of $1.5 \mathrm{~m}$ can automatically adjust the water content. The temperature control accuracy is $\pm 1^{\circ} \mathrm{C}$. Each wetting/drying cycle was $24 \mathrm{~h}$. The specimens were immersed in a $3.5 \% \mathrm{NaCl}$ solution for $10 \mathrm{~h}$, followed by drying at $40^{\circ} \mathrm{C}$ for $14 \mathrm{~h}$. The specimen series FH- 3 and DFH- 3 and FH- 6 and DFH- 6 were exposed for 3 months and 6 months, respectively.

2.4. Bending Test Set-Up and Procedures. The tests were carried out in a servohydraulic SDS500 test machine with a maximum capacity of $500 \mathrm{kN}$, subjected to a four-point bending set-up as shown in Figure 2. Deflections were measured at middle of the specimens using a potentiometer. All data were automatically recorded by a data logging system (TDS-530). The crack width was observed by a microscope. During loading, the displacements and load were recorded every 1 second.

The RC beams were precracked under fatigue loading which is corresponding to vehicle overloading on a highway bridge during one year [22]. The fatigue loading parameters, including loading patterns and number of loading cycles and loading amplitude, were calculated according to the vehicle overloading spectra [22]. Loading was applied sinusoidally, with a frequency of $0.2 \mathrm{~Hz}$. The minimum and maximum cycle loads are $16.8 \mathrm{kN}$ and $73 \mathrm{kN}$, which convert into longitudinal stresses in steel bars of $60.3 \mathrm{MPa}$ to $358.0 \mathrm{MPa}$. The number of cycles is 380 .

All specimens were finally tested under static load, by displacement control at a rate of $0.05 \mathrm{~mm} / \mathrm{sec}$. Loading was stopped when compressive concrete was crushed in the unretrofitted specimens or when the CFRP sheet was tensile ruptured in retrofitted specimens. 
TABLE 1: Specimen details.

\begin{tabular}{lcccc}
\hline Series & $\begin{array}{c}\text { Damaged } \\
\text { status }\end{array}$ & $\begin{array}{c}\text { Strengthening } \\
\text { status }\end{array}$ & $\begin{array}{c}\text { Environmental } \\
\text { status and age }\end{array}$ & $\begin{array}{c}\text { Number of } \\
\text { specimens }\end{array}$ \\
\hline C & $/$ & $/$ & $/$ & 3 \\
D & Damaged & $/$ & $/$ & 2 \\
F & $/$ & Strengthened & Strengthened & Exposed for 3 months \\
DF & Damaged & Strengthened & Exposed for 6 months \\
FH-3 & $/$ & Strengthened & Exposed for 3 months \\
FH-6 & $/$ & Strengthened & Exposed for 6 months \\
DFH-3 & Damaged & Strengthened & & 1 \\
DFH-6 & Damaged & & & \\
\hline
\end{tabular}

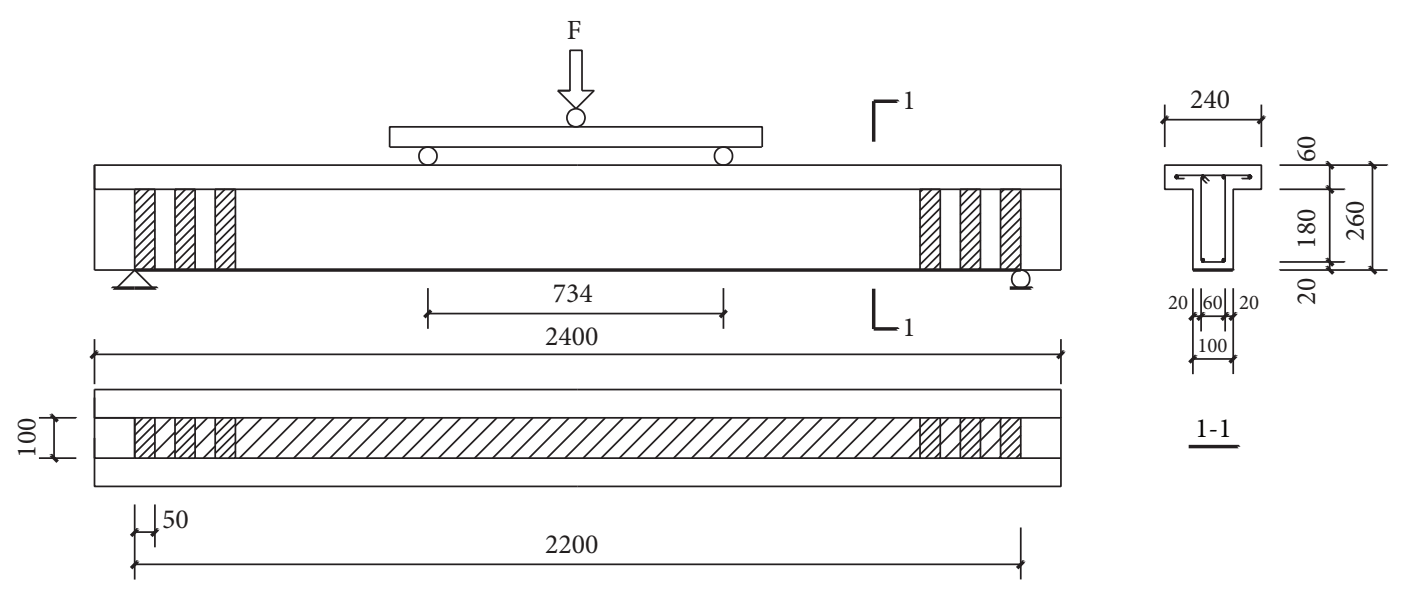

FIGURE 1: Details of the specimen (mm).

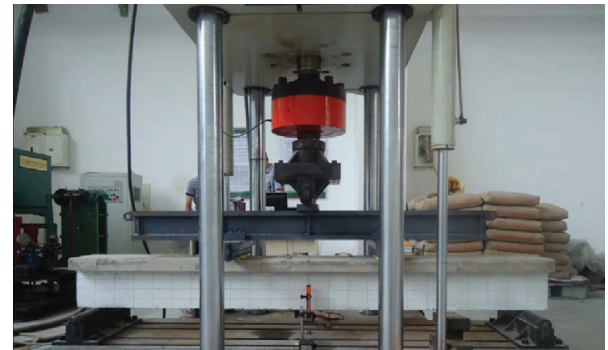

FIgURE 2: Bending test of the beam.

2.5. Chloride Penetration Tests. After bending tests, chloride penetration in specimens FH-3, FH-6, DFH-3, and DFH-6 was tested. The concrete samples were collected from 12 cross sections at $100 \mathrm{~mm}$ spacing in half beam due to symmetry as shown in Figure 3. In each cross section, three samples were collected from two sides and the middle of the web at the depth near the longitudinal steel bars. The locations of the samples were shown in Figure 3. The samples were oven-dried at $50^{\circ} \mathrm{C}$ for $24 \mathrm{~h}$ and thereafter were ground to powder which can pass through $0.15 \mathrm{~mm}$ sieve. Afterwards, concrete powder was dissolved [23] in the following procedures: $2.0 \mathrm{~g}$ powder was put into $40 \mathrm{~mL}$ solution which contains distilled water and concentrated nitric acid in proportion of $85: 15$ for $24 \mathrm{~h}$ and then filtered. After the solution was analysed by $\mathrm{AgNO}_{3}$ titration instrument (Automatic Potentiometric Titrator ZD2), chloride contents in the concrete powder were calculated.

2.6. NEL Tests. NEL method [19-21] was employed to study the chloride diffusion coefficients of the concrete using a concrete electric flux measuring instrument (NELPEU), as shown in Figure 4. The mix proportions of the concrete in NEL test were $1: 2.22: 2.89: 4.92$ (water:cement: sand:aggregate). As shown in Figure 5, 15 concrete cylinders with a diameter of $100 \mathrm{~mm}$ and a thickness of $50 \mathrm{~mm}$ were casted as the samples. Thereafter, they were cured for 28 days. The concrete cylinders were equally distributed in five series with different crack depth. The series G-0 represents sound concrete. The series G-10, G-15, G-20, and G-25 represent the concrete with a $10 \mathrm{~mm}, 15 \mathrm{~mm}, 20 \mathrm{~mm}$, and $25 \mathrm{~mm}$ depth crack, respectively. The width of the cracks is $0.2 \mathrm{~mm}$ which is the maximum allowed crack width in RC structures in Chinese bridge standard (JTG D60-2004) [24]. To artificially preset the crack, a stainless steel thin plate with $0.2 \mathrm{~mm}$ thickness was embedded in the concrete cylinders along a diameter when casting and was moved after 3 -day curing. After immersed in a vacuumed instrument filled with water for $24 \mathrm{~h}$, each specimen was fixed in a testing device. One side of the device was fulfilled with $0.3 \mathrm{~mol} / \mathrm{L}$ $\mathrm{NaOH}$ solution and the other side was fulfilled with $3 \% \mathrm{NaCl}$ 


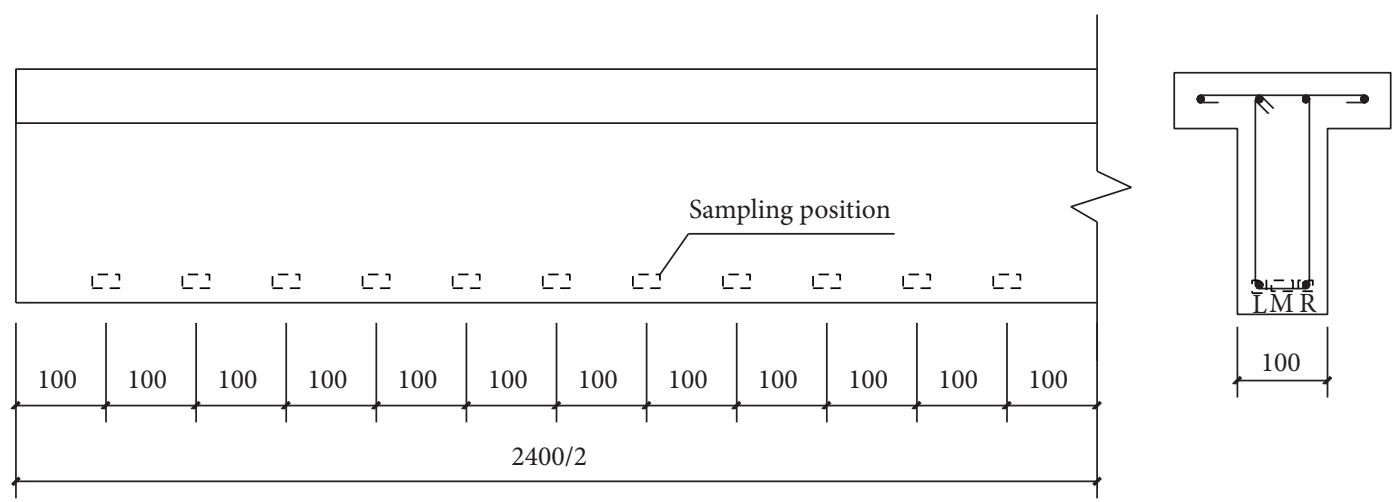

FIGURE 3: Sampling position (mm).

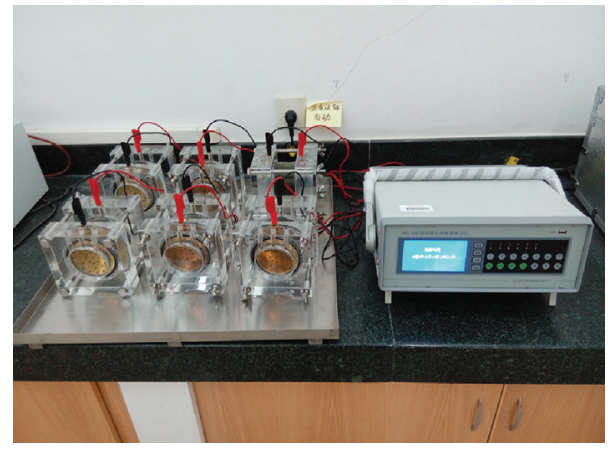

FIGURE 4: NEL-PEU instrument.

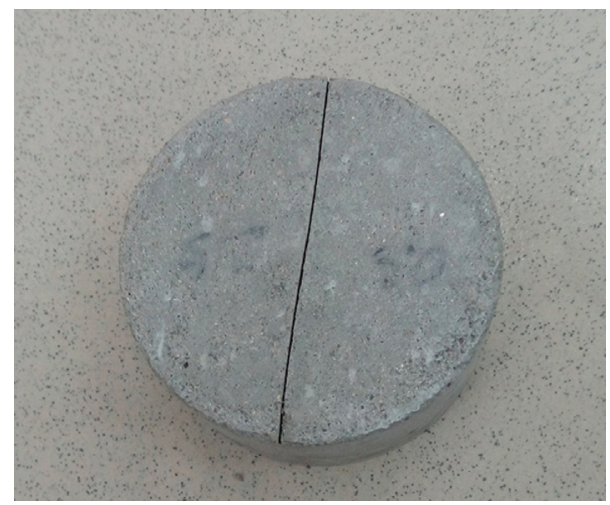

FIGURE 5: Specimen of NEL test.

solution. The electric flux values were recorded after being electrified for $6 \mathrm{~h}$.

\section{Experimental Results and Discussion}

3.1. Precracking. The precracks in the $\mathrm{RC}$ beams were induced by fatigue loading. The damage of the specimens was identified by residual deflection and cracks, as shown in Table 2. The average residual deflections of the beams in series $D$, DF, and DFH were $0.91,1.47$, and $1.11 \mathrm{~mm}$, respectively, which indicates that the fatigue loading weakened the stiffness of
TABLE 2: The results of precracking tests.

\begin{tabular}{lcc}
\hline Series & $\begin{array}{c}\text { Residual crack } \\
\text { width }(\mathrm{mm})\end{array}$ & $\begin{array}{c}\text { Residual } \\
\text { deflection }(\mathrm{mm})\end{array}$ \\
\hline $\mathrm{D}$ & 0.11 & 0.91 \\
$\mathrm{DF}$ & 0.28 & 1.47 \\
$\mathrm{DFH}$ & 0.26 & 1.11 \\
\hline
\end{tabular}

the beams. The average width of the residual cracks in series DF and DFH was wider than $0.2 \mathrm{~mm}$, which is the maximum allowed width of cracks in RC beams in Chinese bridge standard (JTG D60-2004) [24]. This indicates that these beams need to be repaired after the fatigue damage.

3.2. Flexural Capacity. All specimens were statically tested to determine the ultimate strength and deflections. The test results in the form of load-deflection behavior were presented in Figure 6. Average curves of each series were used to avoid cumbersome presentation. Two aspects were noted from Figure 6. Firstly, all the strengthened beams showed a strength enhancement over the unstrengthened beams, but the strengthened beams have very little enhancement in stiffness prior to the unstrengthened beams yielding. Secondly, the precracking and environmental exposure have only marginal effects on the load-deflection curves.

The average ultimate loads and deflections of each series are shown in Figures 7 and 8. The load-deflection curves of series $\mathrm{C}$ and $\mathrm{D}$ are equal, while the ultimate load of D is slightly higher than that of C. The CFRP strengthening increased the ultimate strength of the sound beams in series $\mathrm{F}$ by $85.7 \%$ and the precracked beams in series DF by $73.3 \%$ in comparison with series $C$ and $D$, respectively. This indicates that the CFRP strengthening was less effective for the precracked $\mathrm{RC}$ beams compared to the unprecracked RC beams due to the residual deflection and cracks. In addition, the ultimate deflections of the specimens in series $\mathrm{F}$ and DF were decreased by $20.1 \%$ and $30.8 \%$ in comparison with C and $\mathrm{D}$, respectively, which presents that the CFRP strengthening reduced the ductility of the $\mathrm{RC}$ beams. Comparing the specimens in series F and DF, the wetting/drying cycles for 3 and 6 


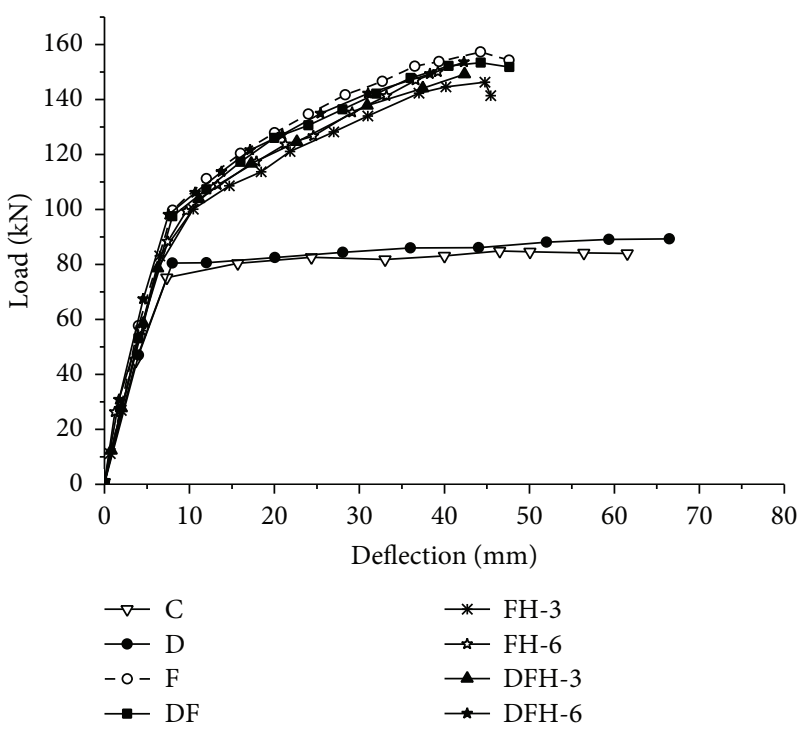

FIGURE 6: Load-deflection curves.

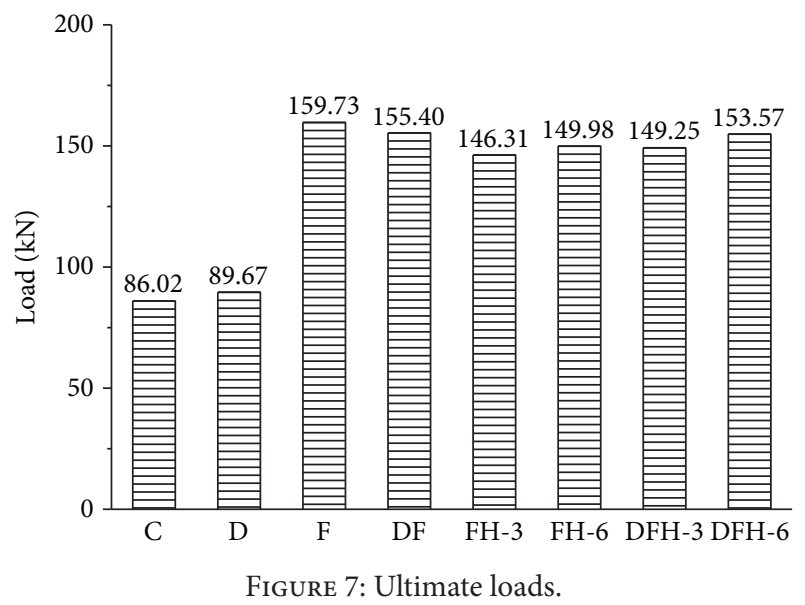

months reduced the ultimate strength of the strengthened $\mathrm{RC}$ beams in series FH-3 and DFH-3 by $6.0 \%$ and in FH- 6 and DFH- 6 by $3.7 \%$, respectively. These clarify that the strength of the specimens exposed to wetting/drying cycles decreased in the first 3 months and then slightly increased in the next 3 months. The environmental exposure has clear effect on the mechanical behavior of the CFRP reinforced concrete members for the first 3 months but this effect is marginal for the next 3 months and even longer period [25]. The strength of the concrete, meanwhile, increased during immersing in the water. The deflections of the specimens in series FH-6 and DFH-6 decreased slightly after 6 months of exposure to environmental condition in comparison with series $\mathrm{FH}$ and DFH. It showed that the hygrothermal environment has marginal effect on the ductility of the strengthened beams. The main cause of the deceases in the strength and ductility of the specimens under environmental exposure is the deterioration of the adhesive bonding caused by moisture diffusion into the adhesive joint $[7,8]$.

The width of the cracks in the middle of the specimens was measured at the load level of $79 \mathrm{kN}$. The average values of

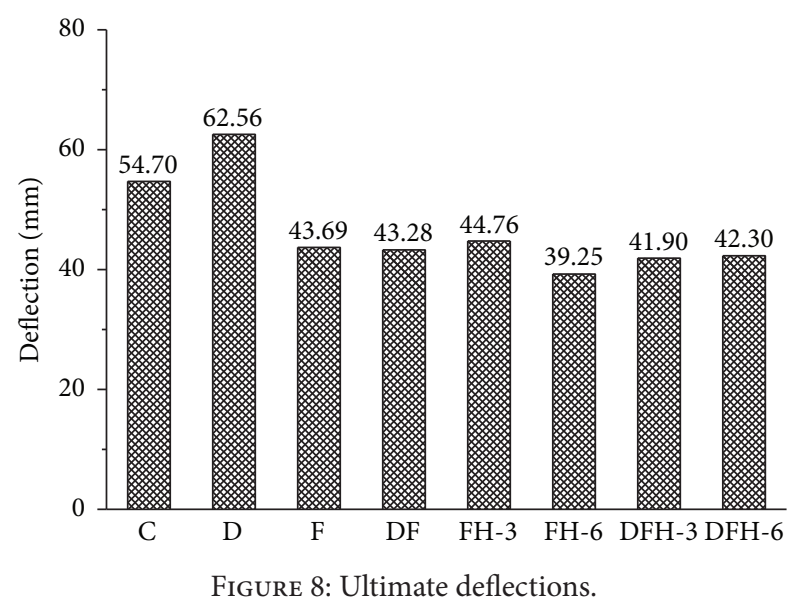

series C, F, DF, and DFH-3 are $0.22 \mathrm{~mm}, 0.12 \mathrm{~mm}, 0.19 \mathrm{~mm}$, and $0.40 \mathrm{~mm}$, respectively. The width of the cracks in the strengthened specimens in series $\mathrm{F}$ was about half of that in the plain control specimens in series $\mathrm{C}$, which indicates that the CFRP strengthening effectively restricts the cracks opening. Due to the residual cracks caused by the fatigue overloading cycles, the strengthened damaged specimens in series DF have wider cracks than the specimens in series F. The width of the cracks in the specimens in series DFH-3 was about two times that of specimens in DF. The reason can be explained by the wetting/drying cycles, which weaken the bonding behavior of the adhesive, resulting in the significant increase of cracks width.

3.3. Chloride Penetration. The chloride profiles of specimens after wetting/drying cycles for 3 and 6 months were shown in Figure 9, from which the effect of the CFRP bonding, precracking, and exposing period on the chloride penetration can be observed.

3.3.1. CFRP Bonding Effect. The chloride contents in the sides of the web (samples L and R) are significantly higher than those in the middle of the web (samples $M$ ), which indicates that the CFRP bonding resisted the chloride penetration into the concrete. The chloride contents in the samples close to the ends of the strengthened beams (FH-3 and FH-6), especially in samples $M$, are obviously higher than those in other locations. This is because the CFRP bonding did not cover the ends of the specimens as shown in Figure 1. Thereby, it has higher chloride permeability.

3.3.2. Precracking Effect. The chloride contents fluctuated along the longitudinal direction in the strengthened precracked beams (DFH-3 and DFH-6). In addition, the average chloride contents in precracked beams (DFH-3 and DFH-6) are higher than those in the sound beams (FH-3 and $\mathrm{FH}$ 6). Furthermore, the chloride contents exactly in the crack location as shown in Figure 9(c) are significantly higher than others. Remarkable corrosion was observed on the steel bars located near this crack as well. As described above, it can be concluded that the cracks in the concrete accelerated the chloride penetration. 


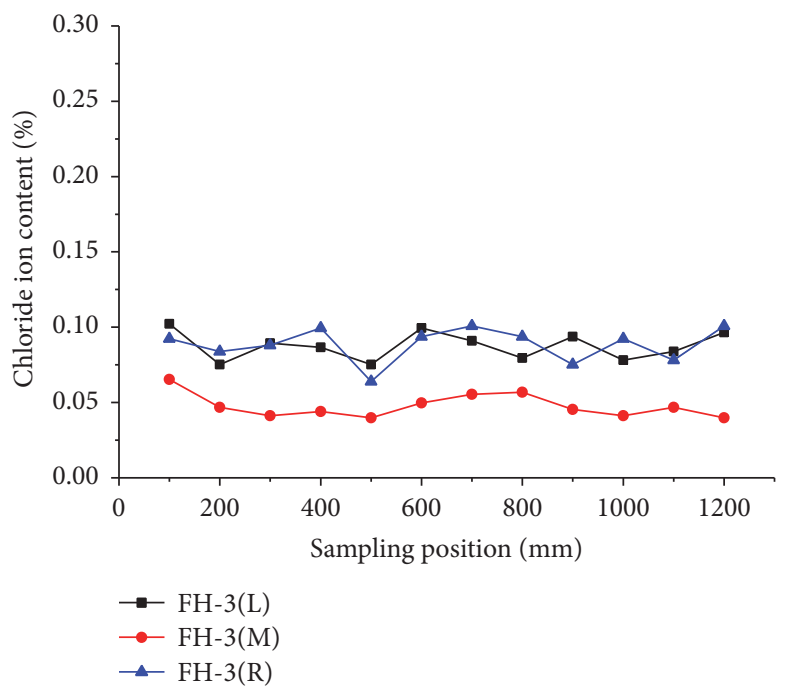

(a) $\mathrm{FH}-3$

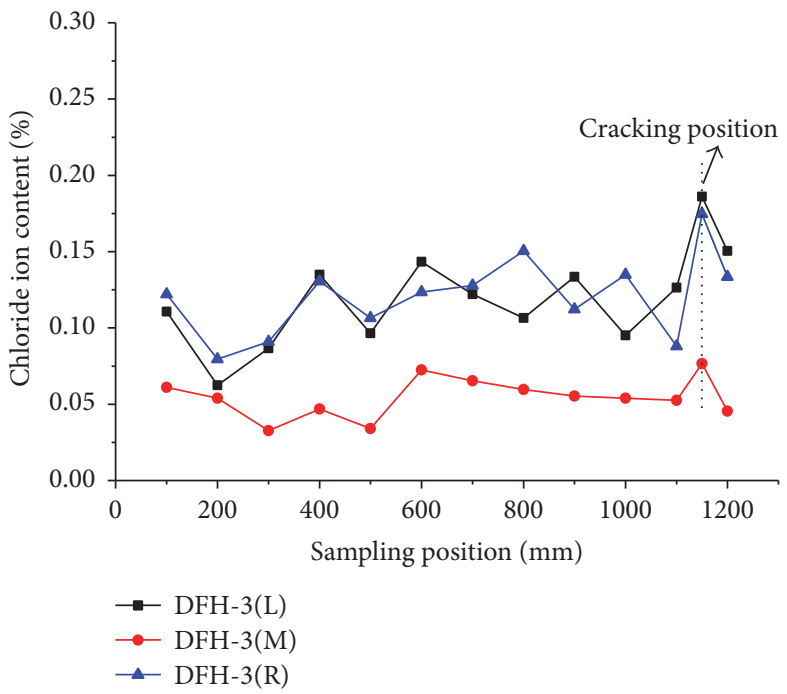

(c) DFH-3

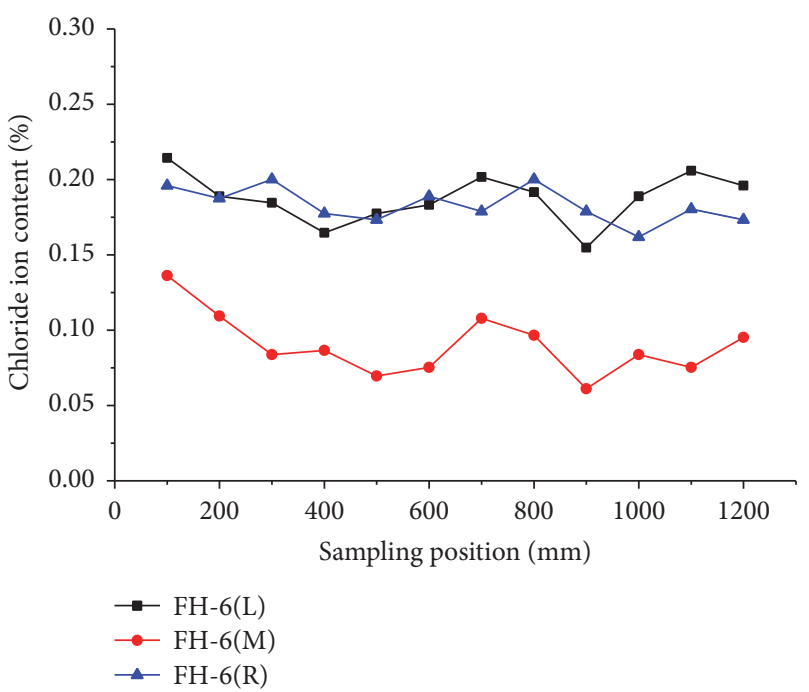

(b) FH-6

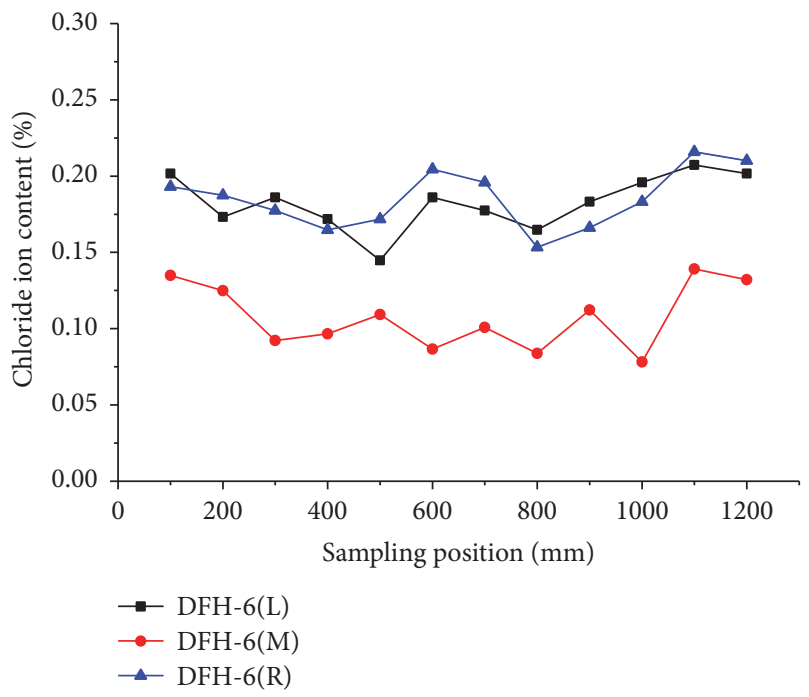

(d) DFH-6

FIGURE 9: Chloride profiles of the specimens.

3.3.3. Exposing Period Effect. The average chloride contents in control specimen $\mathrm{C}$, the specimens exposed to marine environment for 3 months (FH-3 and DFH-3) and 6 months (FH-6 and DFH-6), were $0.017 \%, 0.078 \%$, and $0.142 \%$, respectively. The chloride contents in the specimens subjected to environmental condition for 6 months are almost two times higher than those in the specimens for 3 months, which indicates that the chloride penetration increased with the period of the environmental exposure. Moreover, the chloride content in the specimens exposed for 6 months was higher than $0.1 \%$ which is the allowed value in Code for Construction of Concrete Structures (GB 50666-2011) [26].

3.4. Effect of Crack Depth on Chloride Diffusion Coefficients. The electric flux values $Q$ of series G-0, G-10, G-15, G-20, and G-25 obtained by NEL tests were 2755.21C, 3276.17C,
3324.52C, 3543.57C, and 3751.45C, respectively. The chloride diffusion coefficients calculated by equation of NernstEinstein $[20,21]$ were shown in Figure 10.

The chloride diffusion coefficients of the specimens with $0.2 \mathrm{~mm}$ width crack (G-10, G-15, G-20, and G-25) were $16 \%$ $30 \%$ higher than that of the sound specimens (G-0). The chloride diffusion coefficients increased with the depth of the crack; however, the rate of increase was not pronounced. The chloride diffusion coefficient of the specimens with $25 \mathrm{~mm}$ depth crack (G-25) was only $12 \%$ higher than those with $10 \mathrm{~mm}$ depth crack (G-10).

The average width of the residual cracks in the specimens DFH was $0.26 \mathrm{~mm}$. Meanwhile, the average chloride content in specimens DFH is about $18 \%$ higher than that in specimens $\mathrm{FH}$ without precracks. From the above NEL test results, the increasing rate is in the range of $16 \%-30 \%$, which validates 


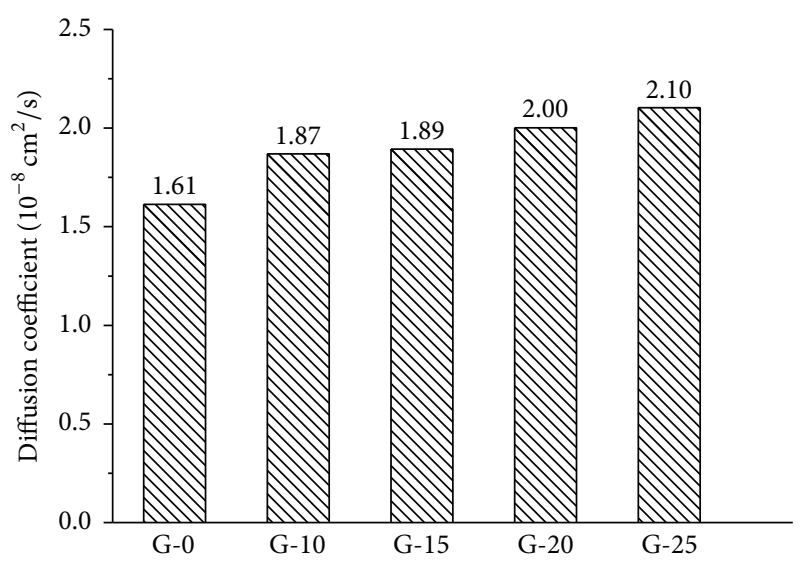

FIGURE 10: Chloride diffusion coefficients.

the effect of the precracking on chloride permeability in $\mathrm{RC}$ beams.

\section{Conclusions}

This paper presented an experimental study on precracked RC T-beams strengthened with CFRP subjected to marine environmental exposure. The RC beams were damaged under fatigue loading, resulting in cracks width in the range of $0.11 \sim$ $0.28 \mathrm{~mm}$. The deterioration of the specimens was produced by placing the beams into salt water under wetting/drying cycles for 3 and 6 months. Flexural capacity and chloride penetration of the specimens were investigated. The following conclusions can be drawn from the experimental results:

(1) The residual deflections and cracks in the RC T-beams damaged by fatigue loading cannot be ignored especially under chloride environment, and those repaired by CFRP can improve the strength significantly and decrease the permeability of chloride.

(2) The strength of the CFRP retrofitted specimens reduced $6.0 \%$ by 3 months of wetting/drying cycles exposure while there was only $3.7 \%$ for specimens which were suffered for 6 months. It indicates that the wetting/drying environmental exposure has more obvious effect on the strength of CFRP strengthened beams in the first 3 months than in the 6 months.

(3) The marine environment weakened the bonding strength of the adhesive and slightly reduced the ductility of the strengthened beams.

(4) CFRP bonding can reduce the chloride penetration into the concrete, especially in the bonding interface, while the cracks in the concrete accelerated the chloride penetration.

(5) NEL test results showed that the chloride diffusion coefficients of the concrete with $0.2 \mathrm{~mm}$ width crack were $16 \%-30 \%$ higher than that of the sound concrete, which also validates the effect of the precracking on chloride permeability in RC beams. In addition, the chloride diffusion coefficients slightly increased with the depth of the crack.

\section{Competing Interests}

The authors declare that there is no conflict of interests regarding the publication of this paper.

\section{Acknowledgments}

The authors thank the following groups for their financial support: National Natural Science Foundation of China (nos. 51278131 and 51202036), New Century Outstanding Talent Support Program Project of China (NCET-13-0739), and Guangdong Provincial Education Department Project of China (2012LYM_ 0056).

\section{References}

[1] G. C. Mays and G. P. Tilly, "Long endurance fatigue performance of bonded structural joints," International Journal of Adhesion and Adhesives, vol. 2, no. 2, pp. 109-113, 1982.

[2] L. C. Hollaway and P. R. Head, Advanced Polymer Composites and Polymers in the Civil Infrastructure, Elsevier Science, Oxford, UK, 2001.

[3] C. C. Choo, T. Zhao, and I. Harik, "Flexural retrofit of a bridge subjected to overweight trucks using CFRP laminates," Composites Part B: Engineering, vol. 38, no. 5-6, pp. 732-738, 2007.

[4] O. Benjeddou, M. B. Ouezdou, and A. Bedday, "Damaged RC beams repaired by bonding of CFRP laminates," Construction and Building Materials, vol. 21, no. 6, pp. 1301-1310, 2007.

[5] T. H. Almusallam, "Load-deflection behavior of RC beams strengthened with GFRP sheets subjected to different environmental conditions," Cement and Concrete Composites, vol. 28, no. 10, pp. 879-889, 2006.

[6] J. Garzón-Roca, J. M. Sena-Cruz, P. Fernandes, and J. Xavier, "Effect of wet-dry cycles on the bond behaviour of concrete elements strengthened with NSM CFRP laminate strips," Composite Structures, vol. 132, no. 12, pp. 331-340, 2015.

[7] K. Benzarti, S. Chataigner, M. Quiertant, C. Marty, and C. Aubagnac, "Accelerated ageing behaviour of the adhesive bond between concrete specimens and CFRP overlays," Construction and Building Materials, vol. 25, no. 2, pp. 523-538, 2011.

[8] A. M. Mahmoud, H. H. Ammar, O. M. Mukdadi et al., "Nondestructive ultrasonic evaluation of CFRP-concrete specimens subjected to accelerated aging conditions," NDT \& E International, vol. 43, no. 7, pp. 635-641, 2010.

[9] D. Zhang, Y. Zhao, T. Ueda, X. Li, and Q. Xu, "CFRP strengthened RC beams with pre-strengthening non-uniform reinforcement corrosion subjected to post-strengthening wetting/drying cycles," Engineering Structures, vol. 127, pp. 331-343, 2016.

[10] D. Zhang, S. Shen, Y. Zhao, W. Jin, and T. Ueda, "Cracking behavior of CFRP laminate-strengthened RC beams with premechanical and postmechanical environmental damage," Journal of Composites for Construction, vol. 19, no. 4, Article ID 04014066, 2014.

[11] M. Otieno, H. Beushausen, and M. Alexander, "Chlorideinduced corrosion of steel in cracked concrete-part I: experimental studies under accelerated and natural marine environments," Cement and Concrete Research, vol. 79, pp. 373-385, 2016.

[12] J. Wu, H. Li, Z. Wang, and J. Liu, "Transport model of chloride ions in concrete under loads and drying-wetting cycles," Construction and Building Materials, vol. 112, pp. 733-738, 2016. 
[13] H.-L. Wang, J.-G. Dai, X.-Y. Sun, and X.-L. Zhang, "Characteristics of concrete cracks and their influence on chloride penetration," Construction and Building Materials, vol. 107, pp. 216-225, 2016.

[14] H. Ye, Y. Tian, N. Jin, X. Jin, and C. Fu, "Influence of cracking on chloride diffusivity and moisture influential depth in concrete subjected to simulated environmental conditions," Construction and Building Materials, vol. 47, no. 5, pp. 66-79, 2013.

[15] T. Ishida, P. O. N. Iqbal, and H. T. L. Anh, "Modeling of chloride diffusivity coupled with non-linear binding capacity in sound and cracked concrete," Cement and Concrete Research, vol. 39, no. 10, pp. 913-923, 2009.

[16] K. Audenaert, G. D. Schutter, and L. Marsavina, "Influence of cracks and crack width on penetration depth of chlorides in concrete," European Journal of Environmental and Civil Engineering, vol. 13, no. 5, pp. 561-572, 2009.

[17] C. Sosdean, L. Marsavina, and G. De Schutter, "Experimental and numerical determination of the chloride penetration in cracked mortar specimens," European Journal of Environmental and Civil Engineering, vol. 20, no. 2, pp. 231-249, 2016.

[18] C. Fu, H. Ye, X. Jin, D. Yan, N. Jin, and Z. Peng, "Chloride penetration into concrete damaged by uniaxial tensile fatigue loading," Construction and Building Materials, vol. 125, no. 10, pp. 714-723, 2016.

[19] H. G. Yin, Y. Li, H. Lv, and Q. Gao, "Durability of sea-sand containing concrete: effects of chloride ion penetration," Mining Science and Technology, vol. 21, no. 1, pp. 123-127, 2011.

[20] X. Lu, "Application of the Nernst-Einstein equation to concrete," Cement and Concrete Research, vol. 27, no. 2, pp. 293-302, 1997.

[21] C. L. Li, X. Y. Lu, and H. X. Zhang, "Rapid test method for determining chloride diffusivities in cementitious materials," Industrial Construction, vol. 628, no. 6, pp. 41-43, 1998 (Chinese).

[22] Z. H. Wang, J. Deng, and D. Y. Wang, "Experimental study on bending capacity of reinforced T-beams after overloading damage," Concrete, no. 6, pp. 31-40, 2014 (Chinese).

[23] Chinese standard, "Testing code of concrete for port and waterwog engineering," J TJ 270-98.

[24] Chinese Standard, "General code for design of highway bridges and culverts," Tech. Rep. JTG D60-2004, 2004.

[25] Y. Huang, Experimental study on durability of CFRP confined concrete subjected to hydrothermal environment [M.S. thesis], Guangdong University of Technology, Guangzhou, China, 2014.

[26] Chinese Standard, "Code for Construction of Concrete Structures," GB 50666-2011. 

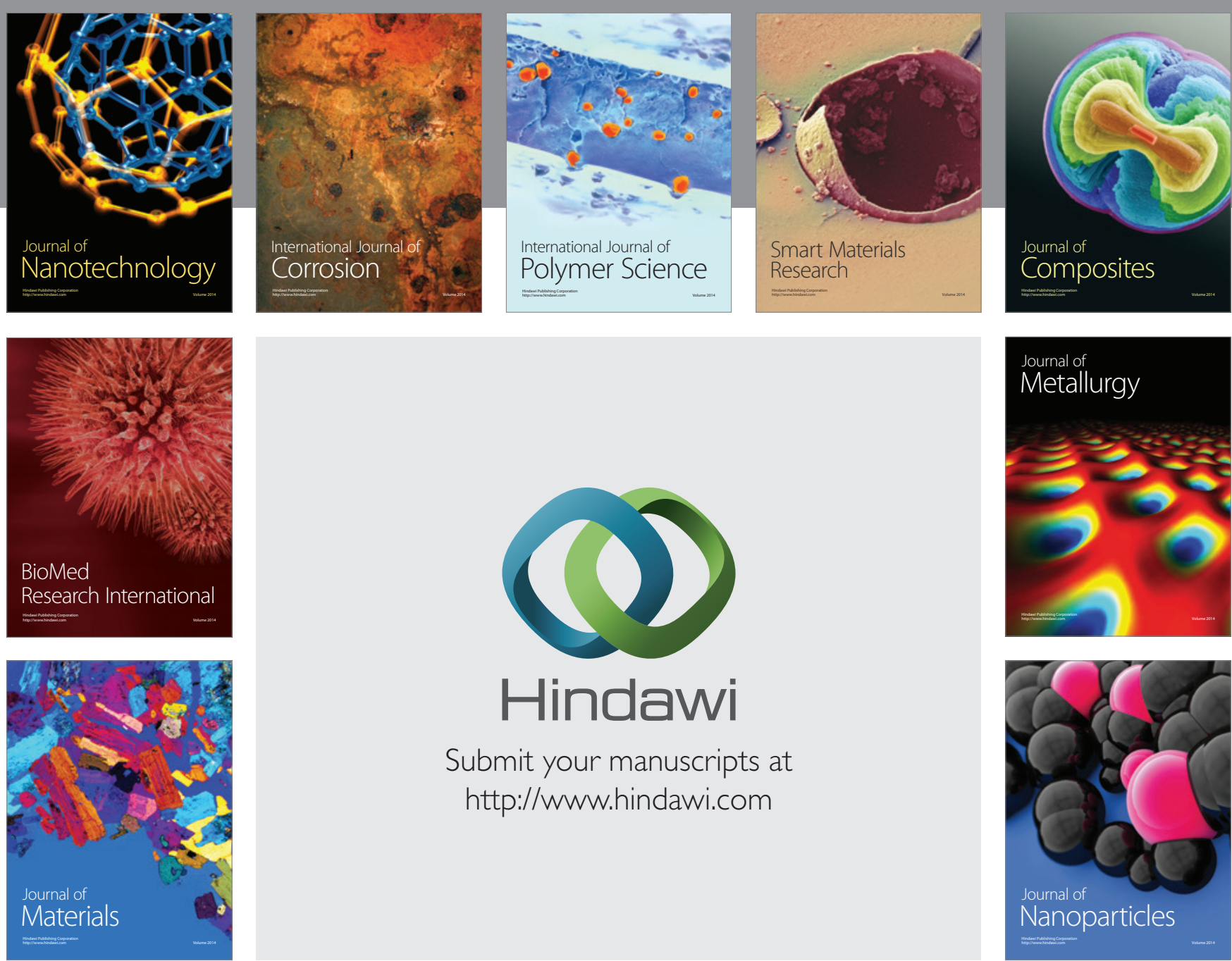

\section{Hindawi}

Submit your manuscripts at

http://www.hindawi.com

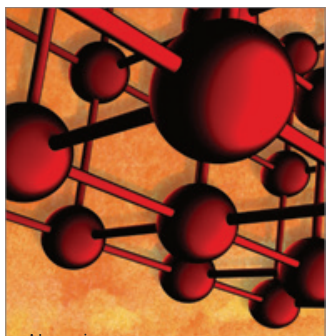

Materials Science and Engineering
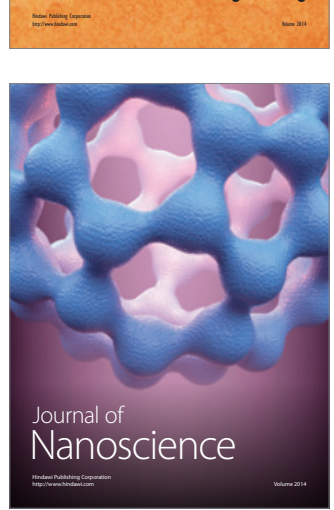
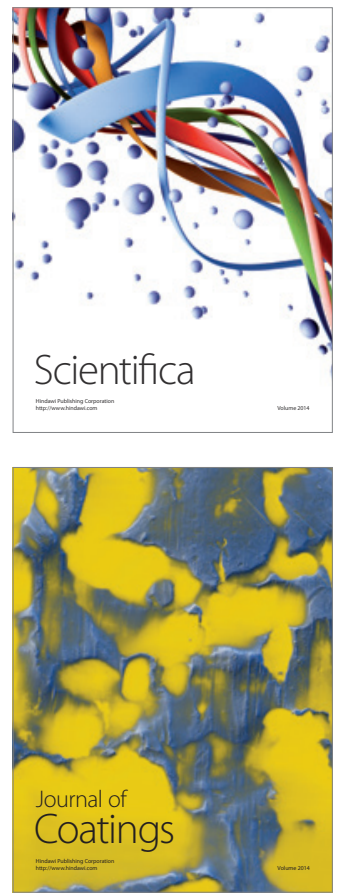
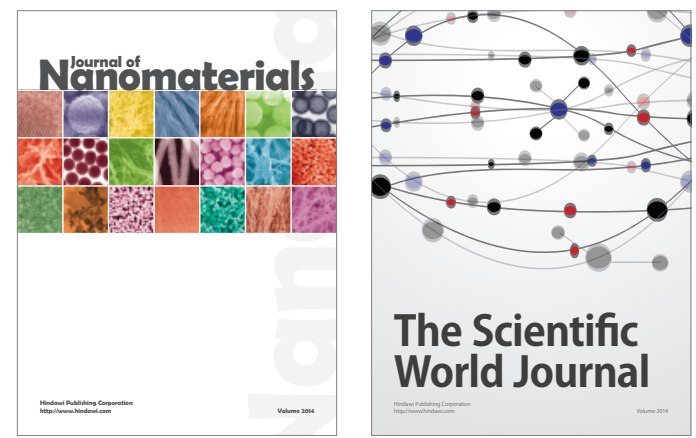

The Scientific World Journal
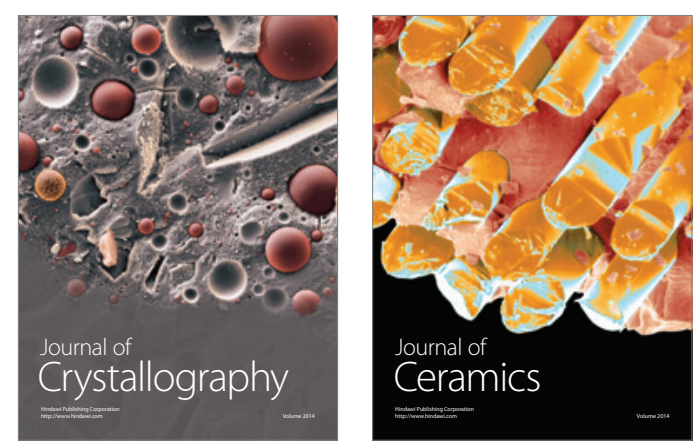
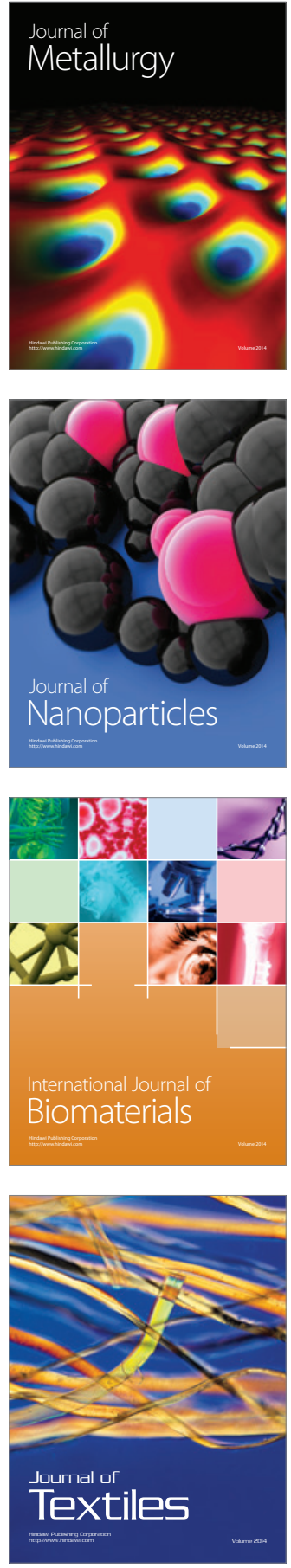